\title{
ANÁLISE DO EFEITO DO ÓLEO ESSENCIAL DE Lippia sidoides SOBRE Atta sexdens (Hymenoptera: Formicidae $)^{1}$
}

\author{
Lucas Kauan Nascimento de Santana², Maria de Fátima Souza Santos Oliveira², Genésio Tâmara Ribeiro², \\ Júlio César Melo Poderoso ${ }^{3}$, Ítala Thainy Barreto Francisco dos Santos ${ }^{2}$, Heloisa Safira Santos Pinheiro², \\ Saiara Santos Silva², Thomaz Soares Santos ${ }^{2}$
}

\author{
${ }^{1}$ Parte de trabalho de pesquisa PAEX \\ ${ }^{2}$ Departamento de Ciências Florestais/ Universidade Federal de Sergipe, Av. Marechal Rondon, s/n, Jd. Rosa Elze, 49100-000, São \\ Cristóvão-Sergipe, Brasil. \\ E-mail: lucas_mqp159@hotmail.com, fatimabiol@hotmail.com, genesiotr@hotmail.com, itala.ufs@hotmail.com, heloisasafira@hotmail. \\ com, sayara.ssilva@gmail.com, thomaz123soares@gmail.com \\ ${ }^{3}$ Secretaria de Meio Ambiente e Desenvolvimento Rural - Prefeitura Municipal de Rosário do Catete, Av. Antônio Freire Soares, n. 184 , \\ 49760-000, Rosário do Catete - Sergipe, Brasil. Email: juliopoderoso@yahoo.com.br
}

RESUMO: As formigas cortadeiras estão entre as principais pragas que ocorrem em plantações florestais e agrícolas no Brasil. Esses insetos cortam material vegetal de forma intensa. e posteriormente o transporta para servir de substrato ao cultivo do fungo simbionte. Devido a esse comportamento, várias formas têm sido usadas no seu controle, sendo os inseticidas organossintéticos (sob forma de iscas) os mais utilizados. Contudo, com 0 uso abusivo destes produtos, impactos negativos no meio ambiente têm ocorrido. Nesse sentido, a busca por métodos alternativos de controle utilizando principalmente produtos de origem vegetal -como os óleos essenciaistem sido intensificada. 0 objetivo deste estudo foi avaliar o efeito do óleo essencial de Lippia sidoides em colônias de formigas Atta sexdens mantidas em laboratório, utilizando o método de nebulização. 0 resultado evidenciou efeito fungicida do óleo essencial de L. sidoides, apontando-o como promissor para ser empregado no controle alternativo de formigas cortadeiras do gênero Atta sp.

Palavras-chave: formigas cortadeiras, fungicida, inseticida botânico, controle

\section{EFFECT ANALYSIS OF Lippia sidoides' ESSENTIAL OIL OVER Atta sexdens (Hymenoptera: Formicidae)}

ABSTRACT: The leaf cutter ants are amongst the main pests that occur in bothforest and agricultural plantations in Brazil. These insects cut the vegetal material and transportit totheir nests in order use as source for the breed of symbiont fungus. Due to this behavior, various methods have been used on its control, being the inorganic insecticides (as baits), the more used ones. However, the abusive usage of these products have been causing negative impacts in the environment. In this context, the seek for alternative ways of control using mainly natural originated ones, such as essential oils, have been intensified. The aim of this study was to evaluate the effect of the Lippia sidoides' essential oil in Atta sexdens colonies kept under laboratory conditions, through the nebulization method. The result evidenced a fungicide effect of the $L$. sidoides essential oil, pointing it as promissory to be used in the alternative control for leaf cutter ants of the genre Atta sp.

Keywords: leaf cutter ants, fungicide, botanic insecticide, control

\section{INTRODUÇÃO}

As formigas do gênero Atta (Hymenoptera: Formicidae) são insetos sociais que vivem em colônias classificadas como permanentes. Devido ao seu hábito de forrageio e ataque à um número elevado de plantas, elas se tornam daninhas às culturas agrícolas e florestais. A sua dificuldade de manejo somada com a ocorrência de diversas colônias em uma única área, acaba por torná-las umas das principais pragas em plantações florestais e não florestais no Brasil (ZANETTI et al., 2002; POWEL; BAKER, 2008).

Devido aos problemas ocasionados pelas formigas cortadeiras, diferentes métodos de controle têm sido desenvolvidos, porém estes ainda se 
limitam ao emprego de produtos químicos, sendo os mais utilizados: isca granulada, termonebulização, pós secos e pós solúveis (OLIVEIRA et al., 2011; ZANETTI et al., 2002). Contudo, além dos altos custos envolvendo a aquisição dos formicidas e da operação de combate, o uso intensivo e não adequado resulta em impactos negativos no meio socioambiental, prejudicando não só ecossistemas, mas também a saúde humana (ZANETTI et al., 2002; ARAÚJO et al., 2015).

Diante da perspectiva socioambiental e econômica quanto ao uso de inseticidas sintéticos no controle de formigas cortadeiras, métodos alternativos passam a ser estudados. Deste modo, surge a possibilidade do uso de inseticidas botânicos, que tratam-se de compostos extraídos de órgãos de plantas. Tal método tem se destacado por seu caráter sustentável, uma vez que estes se degradam com maior rapidez no meio, resultando assim, em menor impacto ambiental (ARAÚJO et al., 2015; MENEZES, 2005; DELLA-LUCIA; SOUZA 2011).

Dos compostos obtidos a partir de partes de plantas, existem os óleos essenciais, cuja composição principal compreende misturas complexas de mono e sesquiterpenos, além de fenilpropanóides, todos produzidos a partir de processos metabólicos secundários. Devido às características organolépticas, estes compostos são utilizados por setores cosméticos, de perfumaria, alimentícios e farmacológicos. Eles apresentam aroma agradável intenso e podem ser obtidos por meio de destilação por arraste à vapor (BAKKALI et al., 2008; BIZZO; HOVELL; RESENDE, 2009).

A Lippia sidoides trata-se de uma espécie arbustiva da vegetação da região Nordeste do Brasil e seu uso é bastante comum para fins medicinais (LORENZI; MATOS, 2002). Entretanto, estudos tem evidenciado potencial inseticida e larvicida a partir do seu óleo essencial (CARVALHO et al., 2003; LIMA et al., 2008).

Diante das vantagens econômicas e socioambientais do uso de inseticidas botânicos somadas ao seu potencial de utilização para fins de controle de pragas, o objetivo deste estudo foi avaliar 0 efeito do óleo essencial de $L$. sidoides em colônias de formigas cortadeiras e Atta sexdens, sob condições de laboratório, utilizando o método de nebulização.

\section{MATERIAL E MÉTODOS}

O experimento foi conduzido no Laboratório de Entomologia Florestal (LEFLO), da Universidade Federal de Sergipe, São Cristóvão - SE. Os formigueiros de $A$. sexdens utilizados foram previamente coletados em áreas do município de São Cristóvão - SE (109236'S de latitude, $37^{\circ} 1993^{\prime}$ O) e em seguida acondicionados em recipientes transparentes com três câmaras (uma central para 0 jardim de fungo, uma de lixo e outra para fornecimento de alimento) e mantidos em uma sala sob condições controladas $(24 \pm 10$ C e U.R > $70 \%$ ). Durante o período de manutenção dos ninhos, foram oferecidos diariamente flocos de aveia e material vegetal de Hybiscus sp., até atingir $1 \mathrm{~L}$ de jardim de fungo, sendo esta a quantidade utilizada para os testes de toxicidade do óleo essencial de L. sidoides. 0 composto foi obtido previamente por meio do método de destilação por arraste de vapor.

A verificação da toxicidade do óleo essencial de $L$. sidoides foi realizada a partir de bioensaios por nebulização nos ninhos jovens de $A$. sexdens mantidos e criados em laboratório. $O$ bioensaio consistiu em três concentrações do óleo essencial, mais a testemunha, com quatro repetições.

As concentrações avaliadas foram 15, 30 e $60 \%$ do óleo essencial, sendo estas previamente definidas por meio de pré-testes in vitro. 0 preparo de cada concentração foi a partir do óleo essencial juntamente com 0 adjuvante (óleo mineral). Tais ingredientes foram homogeneizados manualmente de modo a formar uma calda, sendo em seguida colocados no recipiente plástico (unidade nebulizadora) do conjunto para nebulização individual I-205 $\square$. Para cada ninho contendo $1 \mathrm{~L}$ de jardim de fungo, foi utilizado $5 \mathrm{~mL}$ de calda do produto, padrão utilizado comercialmente (SANTOS-OLIVEIRA et al., 2006). Para o tratamento controle (testemunha), as colônias receberam apenas a nebulização de $5 \mathrm{~mL}$ do óleo mineral.

As avaliações das colônias após nebulização foram realizadas a cada 24 horas, sendo os critérios avaliados: corte de folhas, presença de pedaço de fungo no lixo, desestabilização do fungo simbionte, mortalidade da rainha, condições da colônia e intoxicação das formigas. 


\section{RESULTADOS E DISCUSSÃO}

No tratamento controle, as colônias apresentaram nos primeiros dias de avaliação paralisação do corte de folha e corte de fungo (cerca de 1\%). Todavia, essas atividades foram retomadas a partir do $3^{\circ}$ dia de avaliação. No sétimo dia não havia sinais de intoxicação nos formigueiros e, ao final do bioensaio todos os ninhos estavam ativos novamente.

Porém, em todas as colônias de $A$. sexdens que foram nebulizadas com 0 óleo essencial de $L$. sidoides, foi verificada a ocorrência de sintomas de intoxicação dos formigueiros, constatado por meio do corte do fungo simbionte pelas operárias das formigas; paralisação do corte e incorporação de folhas nos formigueiros; redução do volume do jardim de fungo; e presença de fungos filamentosos, favorecidos por pontos de umidade.

Foi avaliado também a dificuldade de locomoção das operárias e a transferência das crias do interior do jardim do fungo simbionte para a parte superior do fungo, aparentemente na tentativa de salvá-los do ambiente contaminado pelo óleo essencial. Comportamento de certa forma esperado, uma vez que as formigas são insetos cuja dinâmica em comunidade é de caráter altruísta, onde estas cuidam uma das outras e de suas crias (BREVE, 2018).

No bioensaio em que foiaplicadaa concentração de $15 \%$ do óleo essencial de $L$. sidoides, foi verificado que as colônias apresentaram sintomas de intoxicação e redução do jardim de fungo em cerca de $30 \%$ no terceiro dia de avaliação. Posteriormente no sétimo dia, foi observada a presença de fungos filamentosos e sinais de desequilíbrio nos ninhos. Contudo, a partir do décimo quarto dia de avaliação, foi registrado $100 \%$ de inatividade nas colônias.

Nos ninhos que foram aplicados $30 \%$ da concentração do óleo essencial de L. sidoides, os resultados foram semelhantes aos obtidos na concentração de $15 \%$, contudo a redução do jardim de fungo foi em $50 \%$ a partir do terceiro dia de avaliação. Ao décimo quarto dia foi registrado $100 \%$ de inatividade nos ninhos.

$\mathrm{Na}$ maior concentração do óleo essencial de $L$. sidoides $(60 \%)$ ocorreu a intoxicação do ninho diante da redução de $50 \%$ do fungo a partir do $3^{\circ}$ dia. Posteriormente, a partir do sétimo dia de avaliação, foi registrada uma redução dos $50 \%$ restantes do fungo simbionte, resultando na morte total do ninho após esse período.

As avaliações evidenciaram que o óleo essencial de $L$. sidoides reduz 0 jardim do fungo e promove a inatividade dos formigueiros de $A$. sexdens. $O$ potencial fungicida do óleo essencial de $L$. sidoides evidenciado neste bioensaio com formigas cortadeiras coincide com estudos anteriores que visavam a sua eficiência no combate à outros organismos, como 0 realizado por Gonçalves et al. (2015) no controle de Rhizoctonia solani e Sclerotium rolfsii.

A atividade fungicida obtida é atribuída ao efeito dos compostos isolados presentes em óleos essenciais (ABDELGALEIL et al., 2008). Segundo Kumar et al. (2008), as atividades destes e de seus componentes são atribuídas à sua hidrofobicidade, que permite que estes sejam capazes de interagir com a camada lipídica das membranas celulares, resultando em alterações nas suas estruturas, tornando-as menos seletivas.

Quanto à verificação da mortalidade da rainha do ninho, em todos os tratamentos dos bioensaios de nebulização com o óleo essencial de L. sidoides não foi possível constatar ao longo do período de avaliação. No entanto, diante da morte do fungo simbionte e da relação de dependência entre esses organismos (BREVE, 2018), a mesma não terá condições de sobreviver e nem de iniciar um novo formigueiro.

\section{CONCLUSÕES}

Os resultados obtidos com as concentrações do óleo essencial de L. sidoidesa 15, 30 e 60\%, evidenciaram seu potencial fungicida, sendo na concentração de $60 \%$ obteve-se melhor desempenho quando comparada às demais, indicando assim, boas perspectivas para uso desse composto no controle de formigas cortadeiras.

\section{AGRADECIMENTOS}

Agradecemos pelo apoio da PROEX/UFS, CNPq, CAPES e FAPITEC.

\section{REFERÊNCIAS}

ABDELGALEIL, S. A. M.; ABBASY, M. A.; BELAL, A. S. H.; RASOUL, A. Bioactivity of two major constituents isolated from the essential oil of Artemia judaica $\mathrm{L}$. Biosource Technology, 2008. 99, 5947-5950. 
ARAÚJO, M. S.; RODRIGUES, C. A.; OLIVEIRA, M. A.; JESUS, F. G. Controle biológico de formigascortadeiras: o caso da predação de fêmeas de Atta spp. por Canthonvirens. Revista de Agricultura Neotropical, 2015. 2, 8-12.

BAKKALI, F.; AVERBECK, S.; AVERBECK, D.; IDAOMAR, M. Biological effects of essential oils - A review. Food and Chemical Toxicology, 2008. 2, 446475.

BIZZO, H. R.; HOVELL, A. M. C.; RESENDE, C. M. Óleos essenciais no Brasil: aspectos gerais, desenvolvimento e perspectivas. Química Nova, 2009. 32, 588-594.

BREVE, F. Inteligência de Enxames: Colônia de Formigas. Material de Aula - Computação Inspirada pela Natureza. 62p. 2018. Disponível em: https://www. fabriciobreve.com/material/cin/CIN-10-Formigas.pdf> Acesso em 12 de outubro, 2018.

CARVALHO, A. F. U.; MELO, V. M. M.; CRAVEIRO, A. A.; MACHADO, M. I. L.; BANTIM, M. B.; RABELO, E. F. Larvicidal Activity of Essential Oil from Lippia sidoides Cham. Against Aedes aegypti L. Memórias do Instituto Oswaldo Cruz, 2003. 98, 569-571.

DELLA LUCIA, T. M. C.; SOUZA, D. J. Importância e história de vida das formigas-cortadeiras. In: DELLA LUCIA, T. M. C. Formigas-cortadeiras: da biologia ao manejo. Viçosa-MG: UFV, 2011. p. 13-26.

GONÇALVES, A. H.; PEREIRA, A. S.; SANTOS, G. R.S.; GUIMARÃES, L G. L. Atividade fungitóxica in vitro dos óleos essenciais de Lippia sidoides Cham., Cymbo pogoncitratus (D.C.) Stapf. e de seus constituintes majoritários no controle de Rhizoctonia solani e Sclerotium rolfsii. Revista Brasileira de Plantas Medicinais, 2015. 17, 1007-1015.

KUMAR, A.; SHUKLA, R.; SINGH, P.; PRASAD, C. S.; DUBEY, N. K. Assessment of Thymus vulgaris $L$. essential oil as a safe botanical preservative against post-harvest fungal infestation of food commodities. Innovative Food Science and Emerging Technologies, 2008. 9, 575-580.
LIMA, R. K.; CARDOSO, M. G.; GUIMARÃES, L. G. L.; RODRIGUES, V. G.; MELO, B. A.; ANDRADE, M. A.; MORAES, J. C. Caracterização química e estudo comparativo do efeito inseticida do óleo essencial de Lippia sidoides Cham. sobre Tenebrio molitor L. In: 31a Reunião Anual da Sociedade Brasileira de Química. Sociedade Brasileira de Química. 2008.

LORENZI, H.; MATOS, F.J.A. Plantas Medicinais no Brasil: Nativas e exóticas, Nova Odessa-SP. 2002. 521p.

MENEZES, E.L.A. Inseticidas botânicos: seus princípios ativos, modo de ação e uso agrícola. Seropédica, Rio de Janeiro: Embrapa Agrobiologia. 2005. 58p.

OLIVEIRA, M. A.; ARAÚJO, M. S.; MARINHO, G. C.; RIBEIRO, M. M. R.; DELLA LUCIA, T. M. C. Manejo de formigas-cortadeiras. In: DELLA LUCIA T. M. C. Formigas cortadeiras: da biologia ao manejo. ViçosaMG: UFV, 2011. p. 400-419.

POWELL, S.; BAKER, B. Os grandes predadores dos neotrópicos: comportamento, dieta e impacto das formigas de correição (Ecitoninae). In: VILELA, E. F.; SANTOS, I. A.; SCHOEREDER, J. H.; SERRÃO, J. E.; CAMPOS, L. A. O.; LINO-NETO, J. Insetos sociais: da biologia à aplicação. Viçosa, MG: Ed. UFV, 2008. p.1937.

SANTOS-OLIVEIRA, M. F. S.; BUENO, O. C.; MARINI, T. M.; REISS, I. C.Toxicity of Azadirachta indica to leafcutting Ant Atta sexdens rubropilosa (Hymenoptera: Formicidae). Sociobiology, 2006. 47, 1-9.

ZANETTI, R.; CARVALHO, G. A.; SANTOS, A.; SOUZASILVA, A.; GODOY, M. S. Manejo integrado de formigas cortadeiras. Lavras: UFLA, 2002. 16p. 